\title{
Entrainment characteristics of fine particles under high speed airflow
}

\author{
Shaowu Yin $^{1,2, ~}{ }^{,}$Li Wang $^{1,2}$, Chuanping Liu ${ }^{1,2}$, and Lige Tong ${ }^{1,2}$ \\ ${ }^{1}$ School of energy and environmental engineering, University of Science and Technology Beijing, Beijing 100083, China \\ ${ }^{2}$ Beijing Key Laboratory of Energy Saving and Emission Reduction for Metallurgical Industry, University of Science and Technology \\ Beijing, Beijing 100083, China
}

\begin{abstract}
Fine silicon particles (mean size of $2.7 \mu \mathrm{m}$ ) are used as entrained materials, and the entrainment characteristics of fine particles are investigated in a cylindrical fluidized-bed (inner diameter of $28 \mathrm{~mm}$ and height of $1000 \mathrm{~mm})$ under high speed airflow. The effects of the volume flow of gas $\left(Q, 1 \mathrm{~m}^{3} / \mathrm{h}\right.$ to $\left.2.5 \mathrm{~m}^{3} / \mathrm{h}\right)$, the number of holes $(N, 1$ to 4$)$, the size of holes $(D, 1 \mathrm{~mm}$ to $3 \mathrm{~mm})$, and the distance between holes and the upper surface of the material layer $(H,-100 \mathrm{~mm}$ to $200 \mathrm{~mm}$ ) on the entrainment characteristics (entrainment rate $W$ and entrained powder-gas ratio $R$ ) are experimentally studied through orthogonal experiment. The experimental results show that an increase in $Q$ and $H$ constantly improves the entrainment characteristics; a decrease in $D$ enhances such characteristics, whereas the number of holes $N$ has no significant effect on the entrainment characteristics. An optimal operating condition can result in optimal entrainment characteristics $\left(W, 3.1 \mathrm{~g} / \mathrm{min}\right.$ and $R, 0.058 \mathrm{~g} / \mathrm{g}$ ), which can be achieved with a $Q$ of $2.5 \mathrm{~m}^{3} / \mathrm{h}, N$ of $1, D$ of $2 \mathrm{~mm}$ and $H$ of $200 \mathrm{~mm}$
\end{abstract}

\section{Introduction}

Based on the fluidization technology and nitriding reaction of fine silicon powder, a fluidized bed reactor imposes strict requirements on raw silicon powder particle size for preparing fine silicon nitride powder, and requires the less agglomerations or the breaking of silicon aggregates in the entrainment process [1-3]. The dispersed cloud of powder feeding into the reactor must satisfy the following requirements: 1) low velocity to extend the residence time in the reactor; 2) small size to complete the conversion within a reasonable period; and 3) high powder-gas ratio to obtain high production efficiency and gas utilization [4]. Various feeders can be used for the feeding of powder, including mechanical feeders [5], pneumatic feeders [6], and fluidized bed feeders [7], but each of these feeders deals with specific types of materials.

The entrainment of fine particles presents a challenge to industry research. Geldart classified fine particles as group $\mathrm{C}$ particles [8]. A single fine particle cannot remain stable because of its extremely small size (less than $20 \mu \mathrm{m}$ ) and relatively large specific surface area. In this case, fine particles tend to agglomerate to achieve stability [9]. Group C particles also tend to agglomerate in the entrainment process, thereby reducing their entrainment quality. During the entrainment process, friction and collision continuously occur between group $\mathrm{C}$ particles, thereby reducing the distance among them. The van der Waals force emerges when such distance reaches the van der Waals distance scope. The friction between particles also produces static electricity [10]. The liquid bridging force is produced by the water in the fluidized gas, and all these forces will lead to the agglomeration of group C particles [11]. Therefore, many researchers have proposed various methods for preventing the agglomeration of group $\mathrm{C}$ particles or crushing the aggregates of these particles.

To determine the influence of coarse particles on the entrainment characteristics of fine particles, Yang et al. [12] investigated the entrainment characteristics of Geldart group C powder from solid mixtures (groups A and $\mathrm{C}$ ) in a fluidized bed equipped with two vibrators and an agitator. Shin et al. [13] investigated the entrainment characteristics of fine powder from solid mixtures (Geldart groups A and C) in gas-solid fluidized beds with or without a tube. Yin et al. [14] studied the effects of the superficial velocity of nitrogen gas at room temperature, initial loading quantity of fine particles, vibration intensity, and stirring speed on the entrainment characteristics of fine silicon particles in fluidized bed with vibration, stirring, and coarse particles.

Silicon particles (mean size of $2.7 \mu \mathrm{m}$ ) are used as entrained materials, and the entrainment characteristics of fine particles are investigated in a cylindrical fluidized-bed (inner diameter of $28 \mathrm{~mm}$ and height of $1000 \mathrm{~mm}$ ) under high speed airflow. The effects of the volume flow of gas, the number of holes, the size of holes, and the distance between holes and the upper surface of the material layer on the entrainment characteristics are experimentally studied through orthogonal experiment.

\section{Experiment material and methods}

Corresponding author: yinsw@ustb.edu.cn

(C) The Authors, published by EDP Sciences. This is an open access article distributed under the terms of the Creative Commons Attribution License 4.0 (http://creativecommons.org/licenses/by/4.0/). 


\subsection{Experimental apparatus and procedure}

The experimental apparatus, which comprises a air compressor, regulating valve, flow meter, conveying bed, copper tube with holes and bag filter, is schematically shown in Fig. 1. The conveying bed includes a PolyVinylChloride column with a $28 \mathrm{~mm}$ inner diameter and $1000 \mathrm{~mm}$ height. The lower surface of the copper tube with a $4 \mathrm{~mm}$ inner diameter has a number of small holes, which is buried in the material layer. Gas flow can be regulated using the regulating valve. The export of the conveying bed is connected to the bag filter, which has a favourable collection efficiency effect on the entrained powder in the experiment. Fine silicon particles (mean size of $2.7 \mu \mathrm{m}$ ) are used as the entrained materials. Air source uses compressed air generated by air compressor.

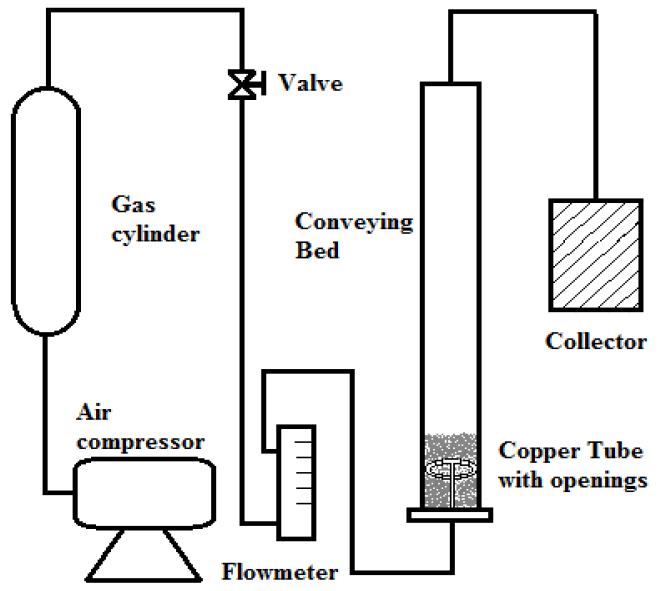

Fig. 1. Schematic diagram of fine silicon powder feeding device

Silicon particles are placed in an incubator at $105^{\circ} \mathrm{C}$ for $24 \mathrm{~h}$ to remove the absorbed water. A weighed quantity of dried silicon particles are introduced into the bed. The copper tube is placed in a designated depth in the conveying bed. The bag filter is weighed using an electronic balance with a $0.001 \mathrm{~g}$ accuracy (denoted as $\left.m_{l}\right)$. The gas supply is activated. The airflow from the nozzle hole forms a high-speed jet airflow, which will impact and crush fine silicon powder and transport them. The entrained silicon powders from the conveying bed are captured by bag filter. The experiment begins after turning on the valve. After $1 \mathrm{~min}$, the entire apparatus is switched off, and the bag filter is reweighed (denoted as $m_{2}$ ). These procedures are repeated five times in each experiment, and the average value is used as the final value for calculating the entrainment characteristics.

\subsection{Experimental design}

Five factors and four levels of orthogonal experiments are designed. The effects of the volume flow of gas $Q$, the number of holes $N$, the size of holes $D$, and the distance between holes and the upper surface of the material layer $H$ on the entrainment characteristics (entrainment rate $\mathrm{W}$ and entrained powder-gas ratio $\mathrm{R}$ ) are experimentally studied through orthogonal experiment.
The experimental factors are set as follows: $Q$ is $1 \mathrm{~m}^{3} / \mathrm{h}$, $1.5 \mathrm{~m}^{3} / \mathrm{h}, 2 \mathrm{~m}^{3} / \mathrm{h}$ and $2.5 \mathrm{~m}^{3} / \mathrm{h} ; D$ is $1 \mathrm{~mm}, 1.5 \mathrm{~mm}, 2 \mathrm{~mm}$ and $3 \mathrm{~mm} ; N$ is $1,2,3$, and $4 ; H$ is $200 \mathrm{~mm}, 100 \mathrm{~mm}, 0 \mathrm{~mm}$ and $-100 \mathrm{~mm}$ (i.e., $100 \mathrm{~mm}$ above the surface of the material layer). In each experiment, the initial charge is $80 \mathrm{~g}$, and the loading height is $400 \mathrm{~mm}$.

Entrainment rate $W$ is defined as follows:

$$
W=\left(m_{2}-m_{1}\right) / t
$$

where $W(\mathrm{~g} / \mathrm{min})$ is the entrainment rate, $m_{1}(\mathrm{~g})$ and $m_{2}(\mathrm{~g})$ are the mass of the bag filter at the beginning and end of the experiment, respectively, and $t(\mathrm{~min})$ is the duration of the experiment.

The mass ratio of entrained powder to the needed nitrogen gas (i.e., entrained powder-gas ratio) $R$ is defined as follows:

$$
R=\frac{60 \times W}{1000 \times Q \times \rho}
$$

where $R(\mathrm{~g} / \mathrm{g})$ is the entrained powder-gas ratio, $Q\left(\mathrm{~m}^{3} / \mathrm{h}\right)$ is the volume flow of gas at room temperature, and $\rho\left(\mathrm{kg} / \mathrm{m}^{3}\right)$ is the density of air at room temperature.

\section{Experimental results}

\subsection{Orthogonal experimental analysis and variance analysis}

\subsubsection{Volume flow of gas $Q$}

Effects of volume flow of gas $Q$ on the entrainment characteristics are shown in Fig. 2. The increase of gas flow increases the apparent gas velocity in the bed. High gas velocity enhances the flow turbulence, and generates a great depth of action to reduce the sizes of agglomerates. $W$ increases from $0.26 \mathrm{~g} / \mathrm{min}$ to $1.56 \mathrm{~g} / \mathrm{min}$ and R increases from $0.012 \mathrm{~g} / \mathrm{g}$ to $0.029 \mathrm{~g} / \mathrm{g}$ when $Q$ increases from $1.0 \mathrm{~m}^{3} / \mathrm{h}$ to $2.5 \mathrm{~m}^{3} / \mathrm{h}$. While the growth rate of $R$ slows down after the $Q$ exceeds $1.5 \mathrm{~m}^{3} / \mathrm{h}$, indicating that the increase in $W$ is less than the increase in $Q$.

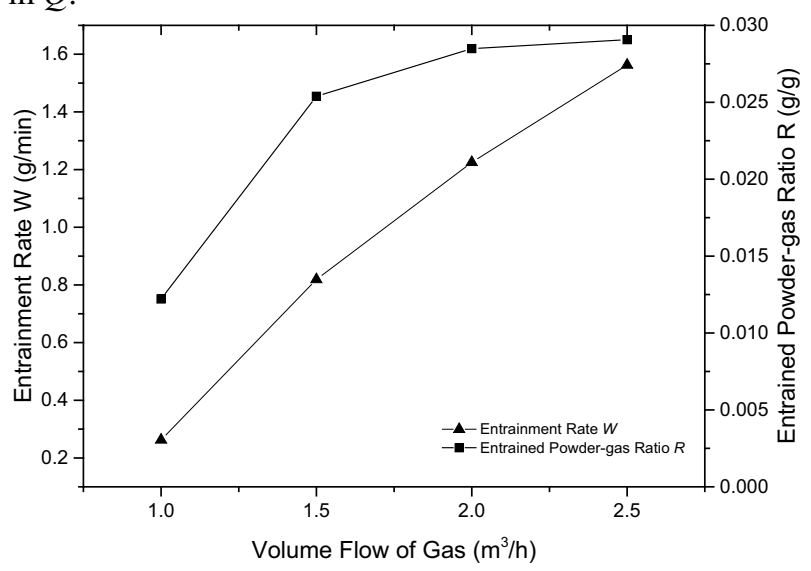

Fig. 2. Effects of volume flow of gas $Q$ on the entrainment characteristics.

3.1.2 Distance between holes and the upper surface of the material layer $H$ 
The distance between holes and the upper surface of the material layer $H$ determines the influence area of impact airflow, which influences the crushing and conveying effect of fine silicon powders in conveying bed. Effects of the distance between holes and the upper surface of the material layer $H$ on the entrainment characteristics are shown in Fig. 3.

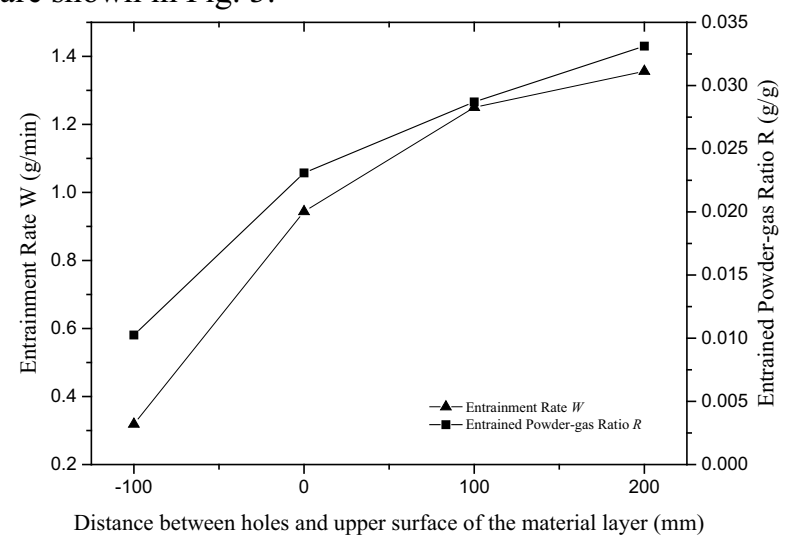

Fig. 3. Effects of the distance between holes and the upper surface of the material layer $H$ on the entrainment characteristics.

When the holes are exposed above the material layer, the airflow from the holes releases into the cavity between the holes and material layer, and the airflow can't effectively play its impact. When the holes are buried in the material layer, the high-speed airflow released by the holes will penetrate a certain thickness of the material layer below, agitate the material layer and crush the agglomerates. Since the bottom of conveying bed is blocked, the airflow entrains fine silicon powders to form the upward motion of gas-solid two-phase flow and achieve the entrainment. When the buried depth of holes increases, the thickness of material layer above the holes increases. Therefore, the probability for fine silicon particles to be entrained out of the conveying bed increases along with $H$. However, the resistance and the load of the air compressor will increase, and it will lead to the slugging easily.

\subsubsection{Number of holes $N$}

The number and the size of the holes on copper tube determine the number, distribution and intensity of the impacting gas stream, thus affecting the effect of crushing the fine particles aggregates.

Effect of number of holes $N$ on the entrainment characteristics are shown in Fig. 4. When the number of holes are small, the impact velocity is large, the airflow entrains fine silicon powders to form the upward motion of gas-solid two-phase flow and achieve higher entrainment rate and entrained powder-gas ratio. As the number of holes increases, the impact velocity decreases and the impact effect weakens. Upward movement of the two-phase flow entrained fine silicon powders encounters downward movement of the impact airflow, which will disperse the impact action of the high speed gas stream and reduce the mixing and crushing effect of airflow on the material layer. But the velocity of impact airflow decreases with the further increase in the number of holes, the hindering effect is also weakened, and the entrainment rate and entrained powder-gas ratio rise.

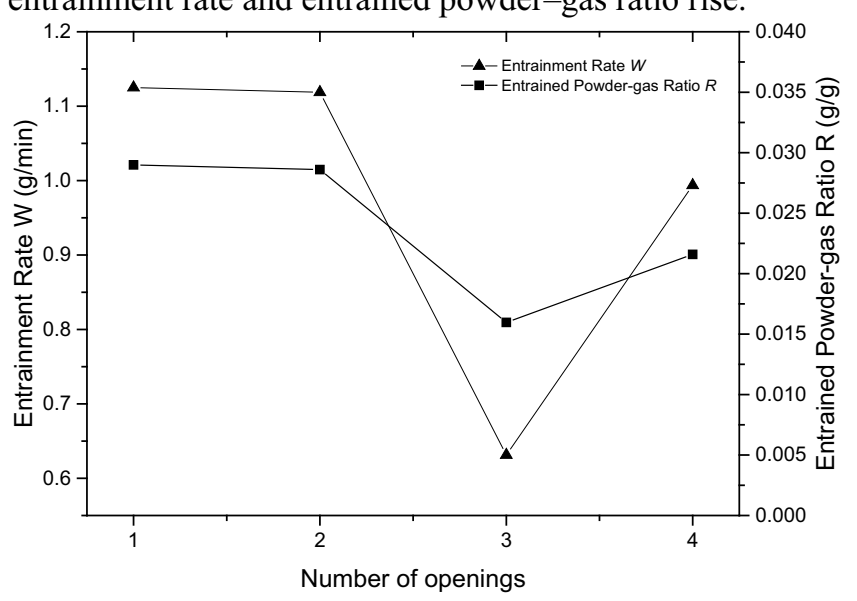

Fig. 4. Effects of number of holes $N$ on the entrainment characteristics.

\subsubsection{Size of holes $D$}

Effects of holes size on the entrainment characteristics are shown in Fig. 5. When the size of holes are small, there are larger impact velocity, higher impact strength, greater the action depth, and higher entrainment rate and entrained powder-gas ratio. When the hole diameter $\mathrm{D}$ is $1 \mathrm{~mm}$, and the number of holes $\mathrm{N}$ is 1 , the gas velocity at the outlet of the holes are about $884.2 \mathrm{~m} / \mathrm{s}$ (supersonic speed) at the $2.5 \mathrm{~m}^{3} / \mathrm{h}$ of the gas flow, so there is danger of burst at the pipeline interface.

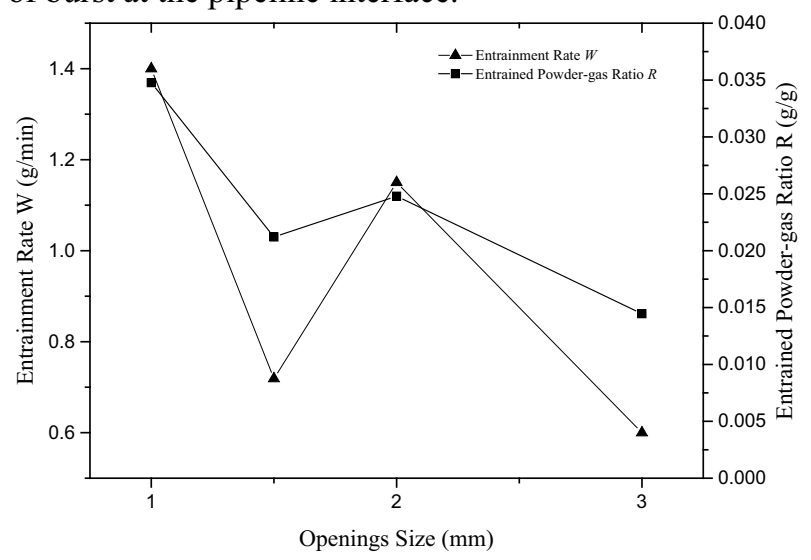

Fig. 5. Effects of holes size on the entrainment characteristics.

\subsection{Analysis of variance}

The variance analysis of $Q, N, D$, and $H$ is performed according to the calculated orthogonal experimental results. Tables 1 and 2 show the variance analysis results for $W$ and $R$, respectively.

$Q$ and $H$ both significantly affect $W$, but only $H$ significantly influences $R$. Given that this study aims to obtain a high $R$, the optimal level combination conditions are set as follows: $Q$ is $2.5 \mathrm{~m}^{3} / \mathrm{h}, D$ is $1.0 \mathrm{~mm}$, $N$ is 1 , and $H$ is $200 \mathrm{~mm}$.

In order to investigate the optimal combination of hole size and number under $2.5 \mathrm{~m}^{3} / \mathrm{h}$ flow rate, some experiments are investigated through control variable 
experiments. The experimental results show that there are still airflow clogging under the conditions of hole diameter $1 \mathrm{~mm}$ and hole number 3; Entrainment rate and entrained powder-gas ratio are generally low when the $D$ is $1.5 \mathrm{~mm}$, which may be due to the large flow resistance at the square hole and the weakening of airflow impact. To sum up, an optimal operating condition can result in optimal entrainment characteristics $(W, 3.1 \mathrm{~g} / \mathrm{min}$ and $R$, $0.058 \mathrm{~g} / \mathrm{g}$ ), which can be achieved with a $Q$ of $2.5 \mathrm{~m}^{3} / \mathrm{h}$, $D$ of $2 \mathrm{~mm}, N$ of 1 , and $H$ of $200 \mathrm{~mm}$.

Table 1. Variance analysis results of the four factors to investigate entrainment rate $W$.

\begin{tabular}{cccccc}
\hline $\begin{array}{c}\text { Sources of } \\
\text { variation }\end{array}$ & $\begin{array}{c}\text { Sum of } \\
\text { squares } \\
S S\end{array}$ & $\begin{array}{c}\text { Degree } \\
\text { of } \\
\text { freedom } \\
d f\end{array}$ & $\begin{array}{c}\text { Mean } \\
\text { square } \\
\text { deviations } \\
M S\end{array}$ & $\begin{array}{c}\text { Value } \\
\text { of } \mathrm{F}\end{array}$ & $\begin{array}{c}\text { Critical } \\
\text { value } \\
\mathrm{Fa}\end{array}$ \\
\hline$D$ & 1.67 & 3 & 0.56 & 6.30 & \\
$N$ & 0.65 & 3 & 0.22 & 2.44 & $\mathrm{~F}_{0.01}(3,3)$ \\
$Q$ & 3.76 & 3 & 1.25 & 14.20 & $=29.46$ \\
$H$ & 2.61 & 3 & 0.87 & 9.85 & $=9.28$ \\
Error & 0.26 & 3 & 0.09 & & \\
\hline
\end{tabular}

Table 2. Variance analysis results of the four factors to investigate powder-gas ratio $R$.

\begin{tabular}{cccccl}
\hline $\begin{array}{c}\text { Sources of } \\
\text { variation }\end{array}$ & $\begin{array}{c}\text { Sum of } \\
\text { squares } \\
S S\end{array}$ & $\begin{array}{c}\text { Degree of } \\
\text { freedom } \\
d f\end{array}$ & $\begin{array}{c}\text { Mean } \\
\text { square } \\
\text { deviations } \\
M S\end{array}$ & $\begin{array}{c}\text { Value } \\
\text { of } \mathrm{F}\end{array}$ & $\begin{array}{c}\text { Critical } \\
\text { value } \\
\mathrm{Fa}\end{array}$ \\
\hline$D$ & 0.00086 & 3 & 0.00029 & 5.78 & \\
$N$ & 0.00047 & 3 & 0.00016 & 3.12 & $\mathrm{~F}_{0.05}(3,3)$ \\
$Q$ & 0.00075 & 3 & 0.00025 & 5.01 & $=\begin{array}{l}\mathrm{F}_{0.1}(3,3) \\
H\end{array}$ \\
\hline & 0.0012 & 3 & 0.00039 & 7.92 & $=5.39$ \\
Error & 0.00015 & 3 & 0.000050 & & \\
\hline
\end{tabular}

\section{Conclusions}

Using the self-designed high-speed airflow impact fine silicon powder feeding device, the effects of the volume flow of gas $Q$, the number of holes $N$, the size of holes $D$, and the distance between holes and the upper surface of the material layer $H$ on the entrainment characteristics (entrainment rate $W$ and entrained powder-gas ratio $R$ ) are experimentally studied through orthogonal experiment. The following conclusions were obtained:

(1) $W$ and $R$ increase obviously with the increase of $Q$ from $1 \mathrm{~m}^{3} / \mathrm{h}$ to $2.5 \mathrm{~m}^{3} / \mathrm{h}$; but when $Q$ exceeds $1.5 \mathrm{~m}^{3} / \mathrm{h}$, the rising trend of $R$ is slowed down.

(2) Under the premise of unobstructed gas flow, reducing $D$ and $N$ is conducive to enhance the mixing and crushing effect of impact airflow, which can get higher $W$ and $R$, but the fluidization and transport of rising two-phase flow will be hindered if excessive jet holes are arranged in a small diameter conveying bed.

(3) When the holes are exposed above the material layer, the airflow can't effectively play its impact, and even obstruct the up-flow of the two-phase flow. When the holes are buried in the material layer, the high-speed airflow will agitate the material layer and crush the agglomerates. The deeper the buried depth, the better the transport effect, but the resistance is greater.

(4) The optimal operating conditions in this work are set as follows: $Q$ is $2.5 \mathrm{~m}^{3} / \mathrm{h}, D$ is $2 \mathrm{~mm}, N$ is $1, H$ is 200 $\mathrm{mm}$.

This work was supported by the National Key Research and Development Program of China (No.2016YFB0601101), and the Beijing Higher Education Young Elite Teacher Project [No.YETP0360].

\section{References}

1. H.Z. Li, M.S. Guo, J. Chem. Ind. Eng. 01, 52 (2013)

2. L. Wang, S.W. Yin, J.C. Dong, P. Chin. CN 1792774 06-28 (2006)

3. S.Y. Shan, Y.M. Wang, Q.M. Jia, J.F. Yang, J.Q. Gao, Z.H. Jin, Bull. Chin. Ceram. Soc. 01, 138 (2009)

4. S.W. Yin, L. Wang, L.G. Tong, S.F Sun, J. Beijing University Chem. Technol. 35, 70 (2008)

5. J.J. Dai, J.R. Grace, Powder Technol. 186, 56 (2008)

6. C. Parker, L.T. Reist, Powder Technol. 107, 36 (2000)

7. T.M. Francis, P.B. Kreider, P.R. Lichty, Powder Technol. 199, 70 (2010)

8. D. Geldart, Powder Technol. 7, 285 (1973)

9. D. Barletta, M. Poletto, Powder Technol. 225, 93 (2012)

10. F. Babick, K. Schiebl, M. Stintz, Adv. Powder Technol. 22, 220 (2011)

11. R.J. Cao, C.G. Lin, L. Sun, Y.L. Zhao, Z. Liu, C.C. Jia, P./M. Technol. 06, 460 (2006)

12. F.M. Yang, L. Wang, S.W. Yin, Y.H. Li, C.P. Liu, L.G. Tong, Ind. Eng. Chem. Res. 52, 1359 (2013)

13. M. K. Shin, E. M. Kim, B. S. Koo, G. Y. Han, K. J. Yoon, D. H Lee, Ind. Eng. Chem. Res. 46, 1408 (2007)

14. S.W. Yin, W.Y. Tang, X.L. Zheng, L.G. Tong, L. Wang, C.P. Liu, Powder Technol. 299, 150 (2016) 